\section{The Differences of Counseling Satisfaction Between Counselees With Counseling Style Matches With Their Personalities and Those Who Are Not}

Journal PSIKODIMENSIA

Volume 17, No. 2, Juli - Desember 2018

ISSN cetak : $1411-6073$

ISSN online : $2579-6321$

DOI 10.24167/psidim.v17i2.1670

Lucia Hernawati; Y. BagusWismanto; RachmadDjatiWinarno

Fakultas Psikologi Universitas Katolik Soegijapranata, Semarang.

e-mail: herna@unika.ac.id

\begin{abstract}
This study aimed to determine the differences in counseling satisfaction between counselees who get counseling services in accordance with the characteristics of his personality and get appropriate counseling style and those who do not. The hypothesis proposed in this study was that there was the influence of counselee personality characteristics, counseling style that was in accordance with the satisfaction of counseling.Two hundred and fifty-three men and women who have lived in Semarang for at least 1 year, aged between 18 and 55 years and came from various professions participated in this research. The recruitment of participants was voluntary to participants who were students whereas for non-student participants, there is assignment from the working institutions. The experimental research method was applied by grouping the subjects in the experimental and control groups randomly. A counseling style that matches the characteristics of the participants' personality was given in the experimental group, whereas in the control group it was not. Further comparison of the experimental and control groups was conducted to prove the differences in counseling satisfaction of both groups. Two instruments used in this study were: (1) the Indonesian version of the NEO Personality Inventory-Revised (NEO-PI-R) developed by Costa \& McCrae (2) Client Satisfaction Questionnaire (CSQ-8). It was found that in general all participants were satisfied with the counseling service received. T-test analysis was found that there was no difference in counseling satisfaction between experimental and control groups.
\end{abstract}

Keywords: Counseling satisfaction, personality characteristics, counseling style

\section{PENDAHULUAN}

Konseling adalah proses
pemberian bantuan dari seorang konselor pada seorang atau sekelompok konseli yang memiliki fungsi psikologikal yang memadai maupun yang memiliki gangguan pada masalah adaptasi. Pada umumnya konseling memiliki target untuk meningkatkan kesehatan mental, pertumbuhan pribadi yang maksimal, penentuan karir dan pengatasan gangguan mental (Gladding, 2004). Tokoh lain yang bernama Smith (2001) menegaskan bahwa konseling memberi kesempatan pada konseli untuk mengeksplorasi, menemukan dan mengklarifikasi cara-cara baru agar dapat hidup lebih bijak dan memuaskan.

Kepuasan konseli dalam mengikuti sesi konseling adalah salah satu hal yang penting diusahakan dalam layanan konseling. Hal ini akan terindikasi pada perolehan informasi yang dibutuhkan konseli, pencapaian insight, pelepasan emosi, dan meningkatnya psychological well being konseli. Selanjutnya kepuasan konseli menjadi parameter efektifitas konseling. Oleh karena itu evaluasi terhadap 
kepuasan konseli pada sesi konseling yang diikuti menjadi penting karena hal tersebut berarti juga evaluasi terhadap efektivitas konseling yang diikuti (Davey, Rostant, Harrop, Goldblatt \& O’leary, 2005). Apalagi bagi konseli Asia termasuk Indonesia (Semarang) cenderung malu menceritakan masalahnya karena akan dianggap tidak mampu menyelesaikan masalah sehingga lebih memilih bicara dengan anggota keluarga daripada mengikuti sesi konseling .Sehingga perlu dievaluasi konseling yang diikuti orang Asia termasuk Indonesia (Semarang) dan mengupayakan agar konseling yang diikuti dapat memuaskannya dan akhirnya datang ke sesi konseling menjadi alternatif pilihan saat memiliki masalah (Fowler, Glenwright, Bhatia \& Drapeu, 2011).

Leibert (2011) menyebutkan bahwa kepuasan konseli pada sesi konseling yang diikutinya diantaranya dipengaruhi oleh faktor kepribadian dan gaya konseling. Karena kepribadian adalah gambaran sekumpulan trait psikologis dan mekanisme dalam diri individu yang diorganisasikan, relatif bertahan dan memengaruhi penyesuaian diri individu dalam lingkungan. Sehingga cara berpikir, merasakan dan berperilaku individu dengan kepribadian tertentu akan bersifat konsisten dalam merespon situasi tertentu pula. Sementara gaya konseling adalah pendekatan konseling atau cara yang dipakai konselor dalam sesi konseling untuk membawanya pada insight.

Saat ini pendukung teori trait yang mengelompokkan trait menjadi lima besar dengan dimensi bipolar yang disebut big five (Pervin \& John, 1992). Selanjutnya McCrae dan Costa pada 1997 mengembangkan alat ukur untuk pengukuran the big five dinamakannya alat ukur tersebut dengan NEO-PI-R (Neuroticism-Extraversion-Openness
Personality Inventory Revised (Larsen \& Buss, 2002).

Adapun faktor-faktor di dalam big five menurut McCrae \& Costa (1997) meliputi (1) Neuroticism. Trait ini menilai kestabilan dan ketidakstabilan emosi. Mengidentifikasi kecenderungan individu apakah mudah mengalami stress, mempunyai ide-ide yang tidak realistis, mempunyai coping response yang maladaptif; (2) Extraversion. Menilai kuantitas dan intensi interaksi interpersonal, level aktivitasnya, kebutuhan untuk didukung, dan kemampuan untuk berbahagi; (3) Openness to Experience. Menilai usahanya secara proaktif dan penghargaannya terhadap pengalaman demi kepentingannya sendiri. Menilai bagaimana individu menggali hal baru; (4) Agreeableness. Menilai kualitas relasi dengan orang lain, rendah hati, lemah lembut, berkecenderungan percaya sepenuhnya pada orang lain, mendahulukan kepentingan orang lain daripada diri sendiri; (5) Conscientiousness. Menilai kemampuan individu di dalam mengorganisasikan berbagai aktivitas, berkecenderungan kompeten, mampu mengorganisasikan apa yang harus dikerjakan, berupaya mencapai apa yang diinginkan, penuh pertimbangan, dan memiliki disiplin diri yang tinggi.

Hernawati dan Primastuti (2017) menemukan bahwa karakteristik kepribadian orang yang tinggal di Semarang cenderung (1)agreeableness, berkecenderungan percaya sepenuhnya pada orang lain, rendah hati, lemah lembut, mendahulukan kepentingan orang lain daripada diri sendiri; (2)conscientiousness, berkecenderungan kompeten, mampu mengorganisasikan apa yang harus dikerjakan, berupaya mencapai apa yang diinginkan, penuh pertimbangan, dan memiliki disiplin diri yang tinggi. 
Kakhnovets (2011) menyebutkan bahwa proses konseling akan diarahkan seperti apa harus sesuai dengan siapa konselinya dan apa yang terbaik untuknya. Lebih spesifik tokoh lain yang bernama Sanderson dan Clarkin (2002) mengatakan bahwa dimensi kepribadian berkontribusi pada pemilihan, proses dan interaksi konseling. Hal ini sejalan dengan pemikiran Xie (2015) yang menyebutkan bahwa keunikan kepribadian konseli perlu dipahami karena hal tersebut akan memengaruhi penentuan cara atau gaya konseling yang dipakai konselor dalam melakukan eksplorasi untuk mengklarifikasi semua hal yang telah dilakukannya dan menemukan cara hidup yang lebih produktif dan memuaskannya. Dengan demikian konselor harus memahami karakter kepribadian konseli melalui asesmen kepribadian agar konselor dapat memutuskan gaya konseling yang sesuai untuknya. Holler (2006) dalam penelitiannya menemukan bahwa gaya konseling yang memuaskan konseli adalah psychoanalitic, client centered, cognitive.

Pada penelitian ini selanjutnya gaya konseling mengacu pada teori yang dikembangkan Holler (2006) namun dihilangkan gaya konseling psychoanalisa. Mengingat pelaksanaannya memubutuhkan waktu yang lama. Secara spesifik gaya konseling cognitive dirujuk menjadi gaya rasional emotive therapy.

Hernawati dan Primastuti (2017) dalam penelitiannya menemukan bahwa ada korelasi antara karakter kepribadian orang Semarang dengan gaya konseling yang disukainya. Hasil penelitian tersebut menunjukkan bahwa (1) orang Semarang yang memiliki kepribadian neuroticism sesuai dengan gaya konseling client-centered; (2) orang Semarang yang memiliki kepribadian extraversion sesuai dengan gaya konseling rational emotive therapy
(RET); (3) orang Semarang yang memiliki kepribadian openness sesuai dengan gaya konseling client-centered; (4) orang Semarang yang memiliki kepribadian agreeableness sesuai dengan gaya konseling client-centered; (5) orang Semarang yang memiliki kepribadian conscientiousness sesuai dengan gaya konseling rasional emotive Therapy (RET).

Sejalan dengan paparan diatas, selanjutnya penelitian ini akan mengetahui pengaruh karakteristik kepribadian orang Semarang dan gaya konseling pada kepuasan konseling orang Semarang.

Banyak teori tentang konseling berasal dari barat, yang belum tentu sesuai bila harus diaplikasikan pada orang yang tinggal di Indonesia khususnya di Semarang. Maka perlu dikembangkan indigenous study yang secara spesifik menemukan kearifan lokal tentang psikologi konseling khususnya konseling yang memuaskan orang yang tinggal di Semarang.

Melalui metoder $\begin{array}{r}\text { eksperimen } \\ \text { desainsimple }\end{array}$
$\begin{aligned} & \text { dengan } \\ & \text { experiment(Experimental }\end{aligned}$
Control Group Design), penelitian ini
akan membuktikan adanya pengaruh
karakteristik kepribadian konseli, gaya
konseling yang sesuai bagi kepuasan
konseling.

METODE

Duaratus lima puluhtiga orang laki-laki dan perempuan yang telah tinggal di kota Semarang minimal 1 tahun, berusia 18 hingga 55 tahun dan berasal dari berbagai profesi berpartisipasi dalam penelitian ini. Rekrutmen partisipan bersifat sukarela pada partisipan yang berprofesi sebagai mahasiswa dan penunjukan institusi tempat kerja pada subyek yang bukan berprofesi sebagai mahasiswa.Metode penelitian eksperimen dengan membagi subyek pada kelompok eksperimen dan 
control dilakukan secara acak. Eksperimen dimulai dengan meminta seluruh subyek mengisi alat tes NEO PIR(The NEO Personality InventoryRevised) sebagai pretest.

Pada kelompok eksperimen diberikan gaya konseling yang sesuai dengan kepribadiannya. Partisipan yang memiliki skor tertinggi pada pada (1) trait neuroticism diberi gaya konseling client-centered; (2) trait extraversion diberi gaya konseling rational emotive therapy ; (3) trait openness diberi gaya konseling client-centered; (4) trait agreeablenessd diberi gaya konseling client-centered; (5) trait conscientiousness diberi gaya konseling grational emotive therapy.Sedangkan partisipan pada kelompok kontrol tidak diberi gaya konseling yang sesuai dengan trait kepribadiannya. Namun dengan gaya konseling realitas. Setelah partisipan mengikuti sesi konseling ratarata 30-45 menit kepadanya diminta mengisi kuesioner kepuasan konseling sebagai posttest. Selanjutnya dilakukan analisa t-tes untukmembandingkan kelompok eksperimen dan kelompok control untuk mengetahui perbedaan kepuasan konseling yang dirasakan subyek penelitian.

Konselor pada penelitian ini adalah tim peneliti dengan dibantu dengan 12 orang mahasiswa tingkat akhir pada Strata 1 dan Strata 2 Fakultas Psikologi Unika Soegijapranata. Mahasiswa yang akan membantu dalam konseling pada penelitian ini diberikan training berserta simulasi terlebih dahulu sampai benar-benar memahami proses yang harus dilakukan.

Terdapat dua alat ukur yang dipakai pada penelitian ini yaitu : (1)The NEO Personality Inventory-Revised (NEO-PI-R) versi bahasa Indonesia yang dikembangkan Costa \& McCrae tahun 1992 dengan reliabilitas 0,825; (2) Client Satisfaction Questionnaire (CSQ8) yang dikembangkan oleh Attkisson \& Greenfield tahun 1994 dan telah diadaptasi kedalam bahasa Indonesia dengan reliabilitas 0,799 .

\section{HASIL}

Seratus empat puluh tiga orang perempuan dan seratus sepuluh orang laki-laki yang berusia 18 hingga 55 tahun berpartisipasi dalam penelitian ini. Dengan perincian 114 orang berprofesi sebagai mahasiswa semester 2 hingga semester 6; karyawan swasta (Hotel MG Setos) 76 orang; dan karyawan pemerintah (Badan Usaha Milik Negara) PT. Pelindo sebayak 63 orang. Selengkapnya pada tabel 1

Tabel 1 Jenis Kelamin dan Pekerjaan Partisipan

\begin{tabular}{lcccc}
\hline Jenis kelamin & \multicolumn{3}{c}{ Pekerjaan partisipan } & Total \\
\cline { 2 - 5 } & Mahasiswa & Swasta & BUMN \\
\hline Perempuan & 85 & 35 & 35 & 143 \\
Laki-laki & 29 & 41 & 41 & 110 \\
\hline Total & 114 & 76 & 76 & 253 \\
\hline
\end{tabular}

Pada kelompok eksperimen 44 orang partisipan diberi konseling dengan gaya konseling client centered, dan 64 orang RET (Rational emotive therapy).
Sedangkan pada kelompok kontrol, seluruh partisipan diberi gaya konseling realitas. Selengkapnya di tabel 2 

Lucia Hernawati: The Differences of Counseling Satisfaction Between Counselees ...

Psikodimensia Vol.17/ 2, 2018 | 176-182 | DOI 10.24167/psidim.v17i2.1720

Tabel 2 Gaya Konseling pada Kelompok Eksperimen dan Kontrol

\begin{tabular}{lcccc}
\hline \multirow{2}{*}{$\begin{array}{l}\text { Kategori } \\
\text { kelompok }\end{array}$} & \multicolumn{3}{c}{ Gaya Konseling } & \multirow{2}{*}{ Total } \\
\cline { 2 - 4 } & Client centered & RET & Realitas & \\
\hline Eksperimen & 44 & 64 & 0 & 108 \\
Kontrol & 0 & 0 & 145 & 145 \\
\hline Total & 44 & 64 & 145 & 253 \\
\hline
\end{tabular}

Pada partisipan di kelompok eksperimen, 25 orang yang berkecenderungan memiliki kepribadian agreeableness diberi gaya konseling client centered, 55 orang yang berkecenderungan memiliki kepribadian conscientiousness diberi gaya konseling RET. Sebelas orang yang berkecenderungan memiliki kepribadian openness diberi gaya konseling client centered dan 1 orang diberi gaya konseling RET. Satu orang yang berkecenderungan memiliki kepribadian extraversion diberi gaya konseling client centered, 8 orang yang berkecenderungan memiliki kepribadian extraversion diberi gaya konseling RET. Enam orang yang berkecenderungan memiliki kepribadian neuroticism diberi gaya konseling client centered dan 1 orang RET. Sedangkan untuk kelompok kontrol, apapun kecenderungan kepribadiannya diberi gaya konseling realitas. Selengkapnya pada tabel 3

Tabel 3 Kepribadian dan Gaya Konseling

\begin{tabular}{ccccc}
\hline Kepribadian & \multicolumn{3}{c}{ Gaya Konseling } & \multirow{2}{*}{ Total } \\
\cline { 2 - 4 } & Client Centered & RET & Realitas & \\
\hline Agreeableness & 25 & 0 & 34 & 59 \\
Conscientiousness & 0 & 55 & 66 & 121 \\
Openness & 11 & 1 & 15 & 27 \\
Extraversion & 1 & 8 & 24 & 33 \\
Neuroticism & 6 & 1 & 6 & 13 \\
\hline Total & 43 & 65 & 145 & 253 \\
\hline
\end{tabular}

Dengan membandingkan mean hipotetik dan mean empirik pada kepuasan konseling, ditemukan bahwapartisipanpada kelompok eksperimen dan kontrol berada pada level puaspadalayanankonseling yang diterima. Selanjutnya dengananalisastatistik t- test ditemukanbahwatidakadaperbedaankepu asankonselingantarakelompokeksperime ndankelompokkontrol. Nilai $\mathrm{t}=-1,418$, $\mathrm{p}>0,05$.

\section{DISKUSI}

Temuan pada penelitian ini tidak mendukung temuan Hernawati \& Primastuti (2017). Partisipan pada kelompok eksperimen dan kelompok kontrol diberikan gaya konseling yang sesuai dengan kepribadian ataupun yang tidak, semuanya memberi kepuasan pada partisipan. Hal ini sesuai pendapat Ribner \& Pas (2002) yang menyebutkan bahwa relasi antara konselor dan konseli yang hangat, penerimaan tanpa syarat, dan empati lebih besar pengaruhnya 
daripada gaya konseling pada layanan konseling dalam mencapai kepuasan konseling.

Oluwatoyin (2016) mengatakan bahwa kepribadian individu sangat unik. Setiap individu memiliki lima trait ( agreeableness, conscientiousness, openness, extraversion, neurotism)

dengan intensitas masing-masing trait yang sangat bervariasi. Sehingga dalam kaitannya dengan pemberian gaya konseling dalam sesi konseling tidak bisa hanya ditetapkan satu gaya konseling. Diperlukan gaya konseling yang terintegrasi.

Terdapat beberapa kelemahan dalam penelitian ini. Pertama, subyek penelitian dengan status mahasiswa ada yang secara sukarela berpartisipasi dalam penelitian ini karena ikut-ikutan teman, ingin memiliki pengalaman sebagai sebagai subyek penelitian namun tidak memiliki masalah. Sedangkan pada subyek bukan mahasiswa, human resources departement (HRD) setempat menunjuk karyawan staff untuk berpartisipasi dalam penelitian ini. Banyak diantara mereka yang tidak mengerti mengapa harus berpartisipasi dalam penelitian ini karena tidak memiliki masalah. Sehingga pemakaian gaya konseling yang sesuai dengan kepribadiannya belum tentu memuaskannya. Namun secara keseluruhan baik subyek di kelompok eksperimen maupun di kelompok kontrol merasa puas atas layanan konseling yang terima. Hal ini bisa terjadi karena bisa jadi penggunaan teknik building rapport yang bagus saat pemberian layanan konseling sehingga subyek merasa didengarkan dan dipahami sehingga merasa puas terhadap layanan konseling diterima. Kedua, pengisian skala kepuasa konseling dilakukan sesaat setelah layanan konseling diberikan. Dilakukan didepan tim peneliti/asisten yang berperan sebagai konselor. Hal ini memberi dampak bisa jadi muncul perasaan tidak nyaman saat memberi penilaian buruk/rendah pada layanan konseling yang diterima. Sehingga subyek memberi penilaian yang mengekspresikan pus dengan layanan konseling yang diterima.

\section{SIMPULAN}

Karakteristik kepribadian dan gaya konseling tidak mempengaruhi kepuasan konseling pada orang Semarang. Hasil penelitian ini bermanfaat bagi pelaksanaan konseling untuk orang Semarang diwaktu yang akan datang untuk mempertimbangkan penggunaan gaya konseling yang terintegrasi. Bukan gaya konsleing tunggal.

Untuk penelitian mendatangkan disarankan (1) saat seleksi subyek penelitian harus dipastikan subyek memiliki masalah yang tidak dapat diselesaikannya sendiri dan membutuhkan bantuan konselor dalam sesi konseling; (2) dipertahankan building rapport yang bagusa ta rakonseli dan konsleor saat pemberian layanan konseling; (3) pengisian skala apapun yang dilakukan setelah konseling tidak dilakukan didepan konselor sehingga subyek dapat member penilaian secara obyektif

\section{DAFTAR PUSTAKA}

Davey, A., Rostant, K., Harrop, K., Goldblatt, J., \& O’leary, P.(2005). Evaluating Genetic Counseling: Client Expectations, Psychological Adjustment and Satisfaction with Service, Journal of Genetic Counseling, Vol.14, No.3. DOI:10.1007/s10897-00050519-6. 
Fowler, D.M, Glenwright, B.J, Bhatia, M, andDrapeu, M. (2011). Counseling Expectation of a Sample of East Asian and Caucasian Canadain Undergraduates in Canada, Canadian Journal of Counselling and Psychotherapy, 45(2)151167Gladding, $\mathrm{S}$. T.(2004).KonselingProfesi yang Menyeluruh, Jakarta, PT Indeks

Hernawati dan Primastuti (2017). Membangun Model Layanan Konseling Psikologis yang Sesuai Dengan Kepribadian Orang Semarang, Laporan Penelitian, Universitas Katholik Soegijapranata.

Holler, T. R.(2006).The Importance of Client Personality in the Prediction of Preference for a Counseling Approach, Memphis University, Disertation

Kaknovets, R. (2011). Relationship Among Personality, Expectations about Counseling, and HelpSeeking Attitudes. Journal of Counseling and Development, 89(1), 11-19.

Larsen, R.j., Buss, David M. (2002). Persoality Psychology: Domain of KnowledgeAbout Human Nature. New York: McGraw Hill.

Lasarus, $\quad$ A.A(1989). Brief Psychotherapy: The Multimodal Model. Psychology, A Journal of Human Behaviour. Vol.26 (1) 610.

Leibert, T.W. (2011). The Dimensions of Common Factors in Counseling, International Journal for the Advancement of Counseling. Vol 33, 127-138.DOI 10.1007/s10447-011-9115-7
Lyddon, W.J.(1989). Personal Epistemology and Preference for Counseling.Journal of Counseling Psychology, Vol.36 4.423-429

McCrae, R.R \& Costa Jr., P.T(1997). Personality Trait Structure as a Human Universality. American Psychologist. Vol 52 (5) 509-516.

Oluwatoyin, B.A. (2016). Evolving Expectations for Personality Traits in Counseling Psychologist in Training, Ife Psychologia, 24(2), ISSN 1117-1421.267-278

Pervin, L.A \& John, O.P, 2001, Personality: Theory and Research, 8 ed. New York: John Wiley \& Sons, Inc.

Ribner, D.S \& Paz, C.K (2002). Client'sView of a Successful Helping Relationship. Journal of Social Work. 47(4) 379-387.

Sanderson, C., \&Clarkin, J.F(2002). Further Use of The NEO-PI-R Personality Dimension in Differential Treatment Planning. In Personality Disorder and The Five-Factor Model Personality.

Smith, H. (2001). Professional Identity for Counsellor. In D.C Locke, J.E.Myers, \& E.L.Herr (Eds), The handbook of Counselling. Thounsand Oaks, CA:Sage

Xie, Q. (2015). Intellectual Style: Their Associations and Their Relationship to Ability and Personality, Journal of Cogntive Education and Psychology, 14(1) 63-76. 